
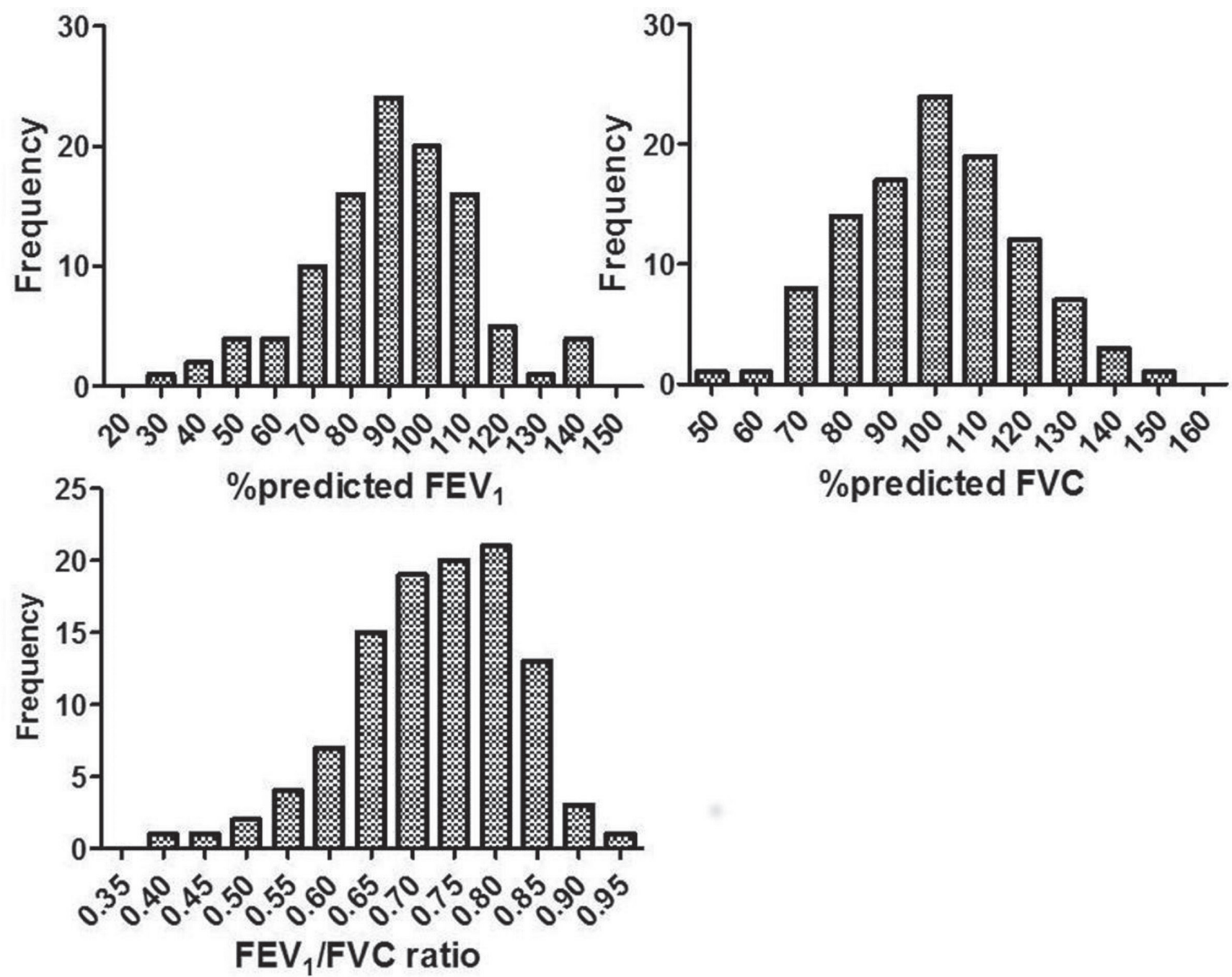

\%predicted FVC

Abstract P214 Figure 1 Frequency distribution of \%predicted $\mathrm{FEV}_{1} / \mathrm{FVC}$ ration in clients attending the Lung Health Clinic

CDAT, and a need to improve uptake of smoking cessation services. An economic model of expected gain in life expectancy and Quality Adjusted Life Expectancy (QALYs) from quitting is in development.

\section{P215 THE INCREMENTAL DISEASE BURDEN ASSOCIATED WITH THE PERSISTENCE OF MORNING, DAYTIME AND NIGHT-TIME SYMPTOMS IN CHRONIC OBSTRUCTIVE PULMONARY DISEASE PATIENTS}

${ }^{1}$ A Munoz, ${ }^{2} \mathrm{~J}$ Bailey, ${ }^{2} \mathrm{R}$ Wood, ${ }^{1} \mathrm{~A}$ Ribera, ${ }^{1} \mathrm{~J}$ Nuevo. ${ }^{1}$ AstraZeneca, Madrid, Spain; ${ }^{2}$ Adelphi Real World, Macclesfield, UK

10.1136/thoraxjnl-2016-209333.358

Introduction The current Global Initiative for Chronic Obstructive Lung Disease Strategy makes limited references to the variability of chronic obstructive pulmonary disease (COPD) symptoms according to the time of day patients experience symptoms, on awakening/morning, in the daytime and at night-time; therefore it's unclear whether specific treatment approaches are needed.

Aims To establish the association between time of day of symptoms and the burden experienced by patients; as measured by validated patient-reported outcomes (PROs), healthcare resource utilisation (HRU) and physician-perceived impact of COPD on patients' lives.

Methods Data were taken from four waves (2012-2016) of the Respiratory Disease Specific Programme (DSP); cross-sectional surveys of COPD patients in France, Germany, Italy, Spain, and the UK. Patients were defined as suffering from symptoms on awakening/morning (M), in the daytime (D), at night-time (N) or combinations of these according to physician-reported time of day of symptoms within the last 4 weeks. Kruskal-Wallis tests assessed statistical significance of outcomes across patient groups. Outcomes included HRU in the last 12 months, EQ-5D-3L with visual analogue scale, Jenkins Sleep Evaluation Questionnaire, COPD Assessment Test, activity impairment (measured by the work productivity and activity impairment questionnaire), and physician-reported impact COPD has on the patient's sleep.

Results In total, 8185 patients receiving treatment were analysed; $25 \%$ suffered no symptoms, $16 \% \mathrm{D}$ only, $17 \% \mathrm{M} / \mathrm{D}$ only, $6 \% \mathrm{D} /$ $\mathrm{N}$ only, $4 \% \mathrm{M}, \mathrm{N}$ or M/N only and $32 \% \mathrm{M} / \mathrm{D} / \mathrm{N}$. Across the four DSP waves, patients suffering any $\mathrm{M}, \mathrm{D}$ or $\mathrm{N}$ symptoms ranged from $46 \%-64 \%, 67 \%-77 \%$ and $38 \%-47 \%$, respectively. All outcomes differed significantly across patient groups (Table 1). In general, $\mathrm{M} / \mathrm{D} / \mathrm{N}$ patients utilised the most healthcare resources, suffered more exacerbations requiring emergency room visits or 
hospital admissions, had higher activity impairment and reported worse quality of life and sleep, whilst asymptomatic patients utilised the least resources and reported the best quality of life and sleep. The remaining groups suffered similar levels of burden.

Conclusions In this analysis, patients experiencing morning, daytime and night-time symptoms have the worst PROs and more disease burden. Clearer recognition of symptom burden and an individualised treatment approach may be warranted for these patients.

\begin{tabular}{|c|c|c|c|c|c|c|}
\hline $\begin{array}{l}\text { Outcomes } \\
\text { (Mean, S. } \\
\text { D.) }\end{array}$ & $\begin{array}{l}\text { None } \\
(\mathrm{n}=2060)\end{array}$ & $\begin{array}{l}\text { D only } \\
(n=1274)\end{array}$ & $\begin{array}{l}\text { M/D only } \\
(n=1378)\end{array}$ & $\begin{array}{l}\text { D/N only } \\
(n=477)\end{array}$ & $\begin{array}{l}M, N \text { or } \\
M / N \text { only } \\
(n=345)\end{array}$ & $\begin{array}{l}M / D / N \\
(n=2651)\end{array}$ \\
\hline $\begin{array}{l}\text { PCP } \\
\text { consultations }\end{array}$ & $2.8(2.9)$ & $3.1(3.0)$ & $3.0(3.0)$ & $3.8(3.2)$ & $3.1(3.1)$ & $4.4(4.5)$ \\
\hline $\begin{array}{l}\text { Specialist } \\
\text { consultations }\end{array}$ & $1.7(1.8)$ & $2.3(2.2)$ & $2.4(2.2)$ & $2.1(2.0)$ & $1.7(1.9)$ & $2.8(2.8)$ \\
\hline ER visits & $0.0(0.3)$ & $0.1(0.4)$ & $0.1(0.4)$ & $0.2(0.5)$ & $0.1(0.4)$ & $0.3(0.6)$ \\
\hline $\begin{array}{l}\text { Hospital } \\
\text { admissions }\end{array}$ & $0.0(0.2)$ & $0.1(0.5)$ & $0.2(0.6)$ & $0.2(0.5)$ & $0.1(0.5)$ & $0.5(1.0)$ \\
\hline $\begin{array}{l}\% \text { activity } \\
\text { impairment }\end{array}$ & $24.6(20.0)$ & $36.8(20.1)$ & $41.0(22.0)$ & $\begin{array}{l}45.0 \\
(19.4)\end{array}$ & $\begin{array}{l}33.7 \\
(22.2)\end{array}$ & $56.4(23.2)$ \\
\hline EQ-5D-3L & $0.89(0.18)$ & $0.85(0.19)$ & $0.81(0.22)$ & $\begin{array}{l}0.80 \\
(0.19)\end{array}$ & $\begin{array}{l}0.86 \\
(0.17)\end{array}$ & $0.69(0.28)$ \\
\hline EQ-VAS & $72.7(15.0)$ & $66.7(14.8)$ & $63.7(15.0)$ & $\begin{array}{l}62.9 \\
(16.1)\end{array}$ & $\begin{array}{l}68.6 \\
(13.9)\end{array}$ & $56.3(17.6)$ \\
\hline CAT & $14.2(7.4)$ & $18.4(7.1)$ & $20.2(6.9)$ & $21.5(6.1)$ & $18.9(7.1)$ & $25.7(6.6)$ \\
\hline $\begin{array}{l}\text { JSEQ } \\
\text { Impact on } \\
\text { Sleep, } \mathrm{n}(\%)\end{array}$ & $2.4(2.9)$ & $3.6(3.3)$ & $4.3(3.9)$ & $5.6(3.4)$ & $4.4(3.5)$ & $8.3(4.8)$ \\
\hline None & $485(42.1)$ & $212(32.9)$ & $189(26.2)$ & $11(4.5)$ & $42(20.1)$ & $60(4.2)$ \\
\hline Low & $512(44.5)$ & $295(45.7)$ & $347(48.1)$ & $90(37.0)$ & $86(41.1)$ & $364(25.2)$ \\
\hline Medium & $121(10.5)$ & $103(16.0)$ & $142(19.7)$ & $\begin{array}{l}105 \\
(43.2)\end{array}$ & $50(23.9)$ & $557(38.6)$ \\
\hline High & $30(2.6)$ & $33(5.1)$ & $39(5.4)$ & $36(14.8)$ & $22(10.5)$ & $367(25.5)$ \\
\hline Constant & $3(0.3)$ & $2(0.3)$ & $4(0.6)$ & $1(0.4)$ & $9(4.3)$ & $94(6.5)$ \\
\hline
\end{tabular}

PCP - Primary care physician; ER - Emergency Room; M - Morning; D - Daytime; N Night time; CAT - COPD Assessment Test; JSEQ - Jenkins Sleep Evaluation Questionnaire

\section{P216 ASSOCIATIONS BETWEEN THE PSYCHOLOGICAL HEALTH OF PATIENTS AND THEIR INFORMAL CARERS IN ADVANCED COPD: WHAT ARE THE RISK FACTORS FOR ANXIETY AND DEPRESSION IN PATIENTS, CARERS AND PATIENT-CARER DYADS?}

${ }^{1} \mathrm{EZ} \mathrm{Mi},{ }^{1} \mathrm{EZ} \mathrm{Mi},{ }^{2} \mathrm{~S}$ Mendonca, ${ }^{2} \mathrm{AC}$ Gardener, ${ }^{2} \mathrm{MC}$ Farquhar. ${ }^{1}$ School of Clinical Medicine, University of Cambridge, Cambridge, UK; ${ }^{2}$ Department of Public Health and Primary Care, University of Cambridge, Institute of Public Health, Cambridge, UK

\subsection{6/thoraxjnl-2016-209333.359}

Introduction Anxiety and depression (AD) are highly prevalent in patients with advanced COPD and their informal carers, and are associated with lower quality of life and increased healthcare use. Previous studies have postulated risk factors for patient $\mathrm{AD}$ in COPD (including dyspnoea, poor functional status and poor selfmanagement) and carer AD (including female gender, insufficient support and high subjective symptom burden). However, little is known about the association between patient and carer $\mathrm{AD}$. We aimed to determine this and factors associated with patient, carer and dyad AD.
Methods Prospective mixed-method interviews with a population-based cohort of 109 pairs of well-characterised advanced COPD patients and their carers. Clinical anxiety and depression (defined as Hospital Anxiety and Depression Scale [HADS] anxiety or depression score $>11$ ) were identified and a dichotomous 'psychological morbidity' (PM) variable created (HADS score $>11$ for either anxiety or depression) due to small sample size. MannWhitney $\mathrm{U}$ tests and multivariate logistic regression identified factors associated with patient $(n=39)$ or carer $(n=30)$ PM.

Results Prevalence of anxiety and depression was 31.2\% and $15.6 \%$ in patients and $26.6 \%$ and $11 \%$ in carers respectively. In univariate analysis, patient and carer PM were significantly associated with each other $(\mathrm{p}=0.005)$, with odds ratio $3.388(95 \%$ CI: 1.414-8.118), and mainly disease-related variables and carer characteristics (including poor coping and unmet support needs), respectively. No demographic factors were significantly associated with patient PM but female gender was associated with carer PM. Table 1 shows the results of multivariate analysis. Finally, dyad PM was associated with male patients/female carers, living apart, parent-child relationship, and more exacerbations.

Conclusions For patients, more exacerbations may indicate disease progression resulting in anxiety, fatigue may limit activity leading to social isolation and depression, and poor self-management may increase symptom burden leading to AD. Patient PM could lead to carer PM by increasing carer burden and impairing intra-dyad communication. Our study, with the strength of a prospective approach and recruitment from primary care, highlights the need to assess $\mathrm{AD}$ in carers of COPD patients (particularly with $\mathrm{AD}$ ), to prevent it with more information and support for carers, and for interventions targeting the dyad.

\section{P217 IMPROVING CARE AND SUPPORT IN ADVANCED COPD - SIX RECOMMENDATIONS FROM THE POPULATION- BASED LIVING WITH BREATHLESSNESS STUDY}

${ }^{1} \mathrm{MC}$ Farquhar, ${ }^{1} \mathrm{G}$ Ewing, ${ }^{2} \mathrm{P}$ White, ${ }^{3} \mathrm{P}$ Burge, ${ }^{4} \mathrm{R}$ Mahadeva, ${ }^{1} \mathrm{AC}$ Gardener, ${ }^{1} \mathrm{C}$ Moore, ${ }^{5} \mathrm{~S}$ Howson, ${ }^{1} \mathrm{~S}$ Booth, ${ }^{3} \mathrm{C}$ Saunders, ${ }^{3} \mathrm{~T}$ Ling. ${ }^{1}$ University of Cambridge, Cambridge, UK; ${ }^{2}$ King's College London, London, UK; ${ }^{3}$ RAND Europe, Cambridge, UK; ${ }^{4}$ Cambridge University Hospitals NHS Foundation Trust, Cambridge, UK; ${ }^{5}$ Cambridge and Peterborough Foundation Trust, Cambridge, UK

\subsection{6/thoraxjnl-2016-209333.360}

Introduction Chronic obstructive pulmonary disease (COPD) is a chronic life-limiting condition with high symptom-burden and carer-burden. National guidance on end of life care calls for quality care for patients with any condition, yet we rely on frameworks developed for cancer with its largely predictable trajectory. Aim To develop evidence-based recommendations to inform a new framework to improve care and support of patients living with advanced COPD and their informal carers.

Methods The Living with Breathlessness Study was a multiplecomponent, population-based, mixed-method longitudinal, multiple-perspective research programme to identify new evidence on health and social care needs and preferences of patients with advanced COPD and their carers. It followed more than 500 patients and carers for up to 18 -months through interview and survey methods. Qualitative data on barriers and facilitators to meeting needs were collected from clinicians. Programme-wide evidence was synthesised to identify recommendations. Stakeholder views were then collected through a workshop and online survey.

Results Six inter-related recommendations emerged, linked by the concept of proactive person-centred care: (1) Stop the 